\title{
LA-UR-21-20182
}

Approved for public release; distribution is unlimited.

Title: $\quad$ Module 4 Hand-Stacking and Remote Approach to Critical Using the Planet/Comet Assembly

Author(s): $\quad$ Sanchez, Rene Gerardo

Grove, Travis Justin

Cutler, Theresa Elizabeth

Intended for: $\quad$ This presentation will be used as part of the training that students get when they take the Nuclear Criticality Safety Class in Nevada.

Issued: 2021-01-08 
Disclaimer:

Los Alamos National Laboratory, an affirmative action/equal opportunity employer, is operated by Triad National Security, LLC for the National Nuclear Security Administration of U.S. Department of Energy under contract 89233218CNA000001. By approving this article, the publisher recognizes that the U.S. Government retains nonexclusive, royalty-free license to publish or reproduce the published form of this contribution, or to allow others to do so, for U.S. Government purposes. Los Alamos National Laboratory requests that the publisher identify this article as work performed under the auspices of the U.S. Department of Energy. Los Alamos National Laboratory strongly supports academic freedom and a researcher's right to publish; as an institution, however, the Laboratory does not endorse the viewpoint of a publication or guarantee its technical correctness. 


\section{Module 4 \\ Hand-Stacking and Remote Approach to Critical Using the Planet/Comet Assembly}

\section{Unclassified LA-UR-21}

Prepared by Rense Sanschez, Travis Grove, and Theresal Cutler 


\section{Goals}

- To ensure students gain a working knowledge of how to apply the " $1 / 2$-way " and " $3 / 4$ " safety rules for performing a "hand-stack" operation.

-To ensure students gain a working knowledge of how changes in moderator and reflector geometry affect the criticality of a system.

-To ensure students gain experience using the Inhour equation relating reactivity and reactor period. 


\section{Module 4 Part 1: Hand-Stacking}

OAK
RIDGE

Lawrence Livermore National Laboratory 


\section{What Do We Want To Do?}

\section{Demonstrate Moderation}

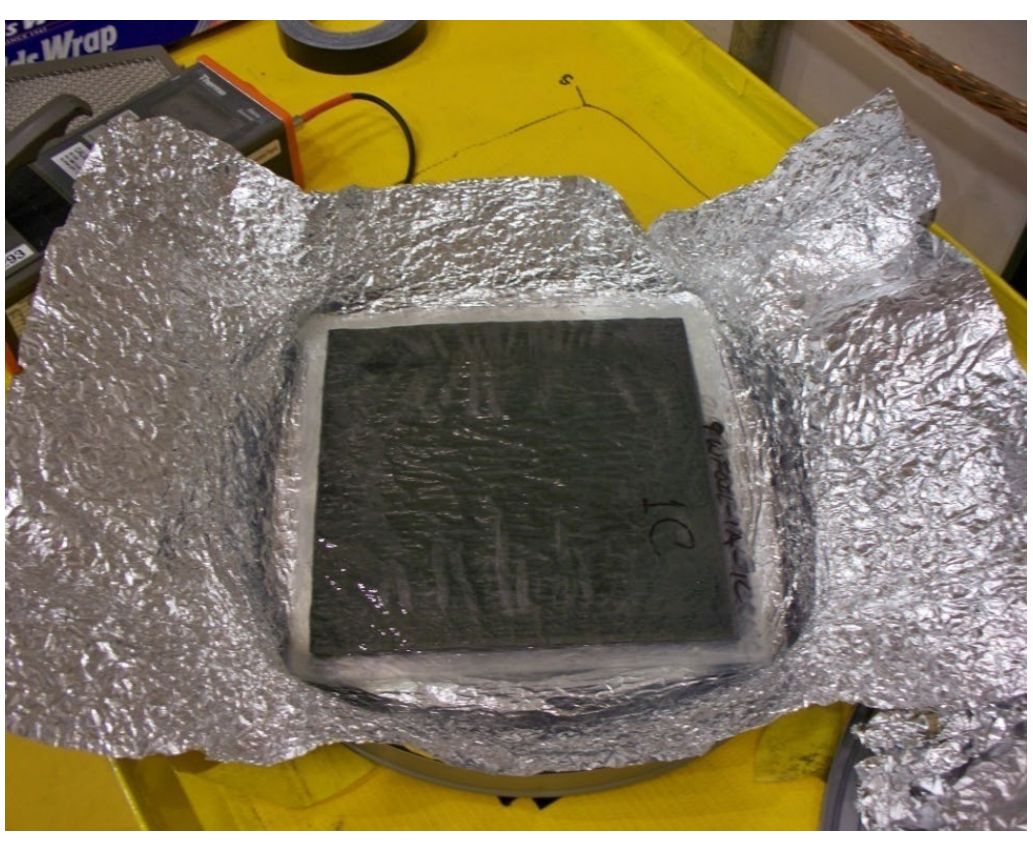

- The poly/lucite plates act as a moderator and reflector

- Lots of hydrogen, a good moderator!

- Mimics a fissile solution system

\section{HOW?}

We want to interleave thin HEU foils in between polyethylene/Lucite plates

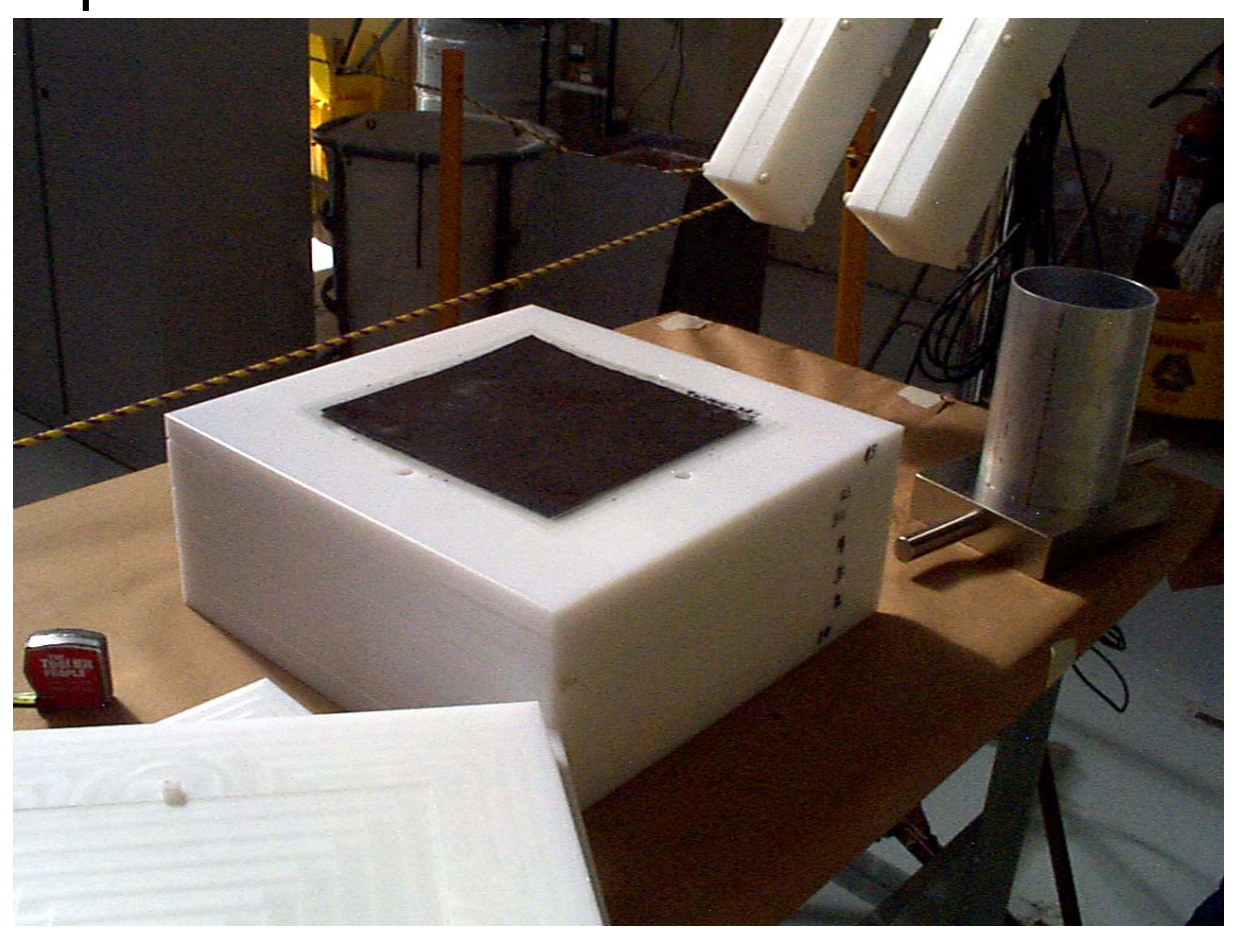

HDP $\mathrm{H}$ density $123 \%$ of $\mathrm{H}_{2} \mathrm{O}$ Lucite $\mathrm{H}$ density $85 \%$ of $\mathrm{H}_{2} \mathrm{O}$ 


\section{Class Foils (HEU)}

Uranium Metal Foils

9.0-in square by 0.003 -in thick

Starting with foils in a Can

Mass per foil: $\sim 70 \mathrm{~g}$

Total number of foils: 26

Total Mass in Can: $\sim 1,800 \mathrm{~g}$

$93.19 w t \% 235 \mathrm{U}$

Average Density: $17.25 \mathrm{~g} / \mathrm{cc}$

${ }^{235} \mathrm{U}$ metal mass limit in CSED: $10,000 \mathrm{~g}$

Why are we ok at the start, if we know we have enough material to go prompt critical? 


\section{Class Foil Experiment}

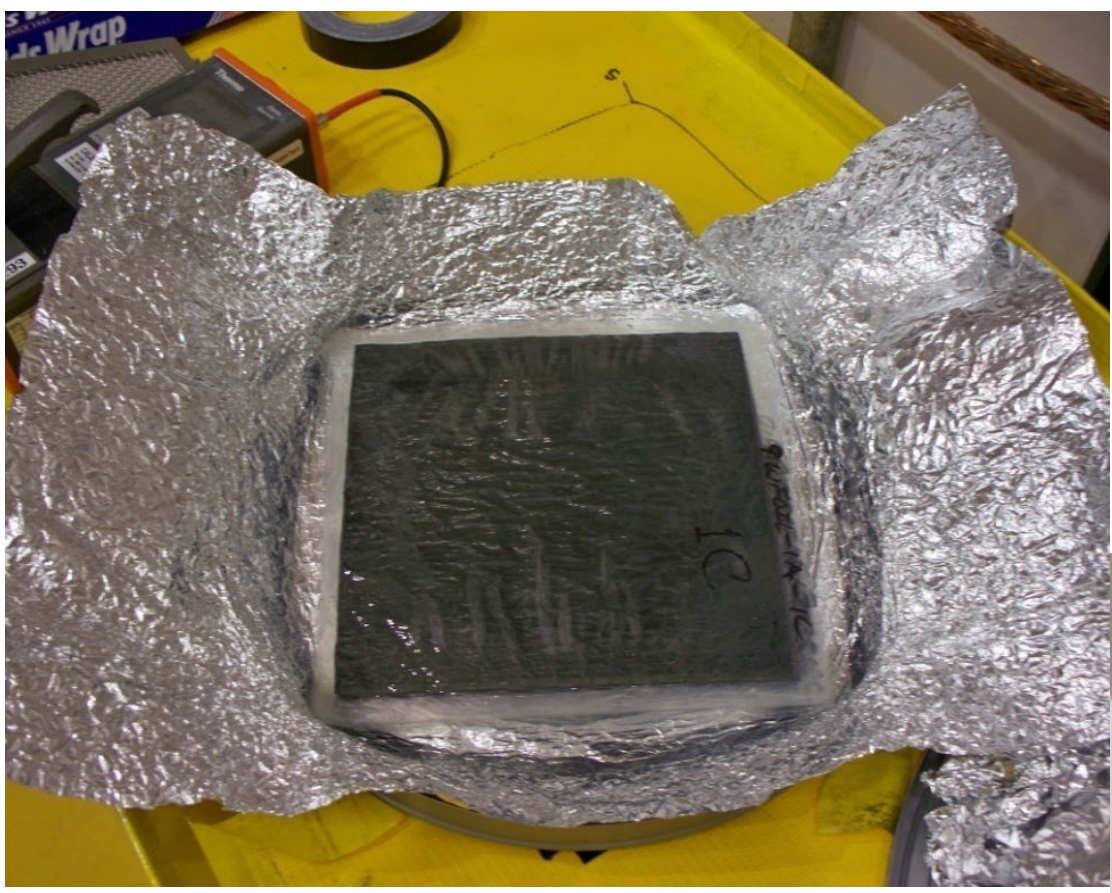

\section{Fuel units consist of}

laminated uranium metal foils and polyethylene or lucite plates

If we stack enough foillucite/poly plate units together, we will achieve a critical configuration

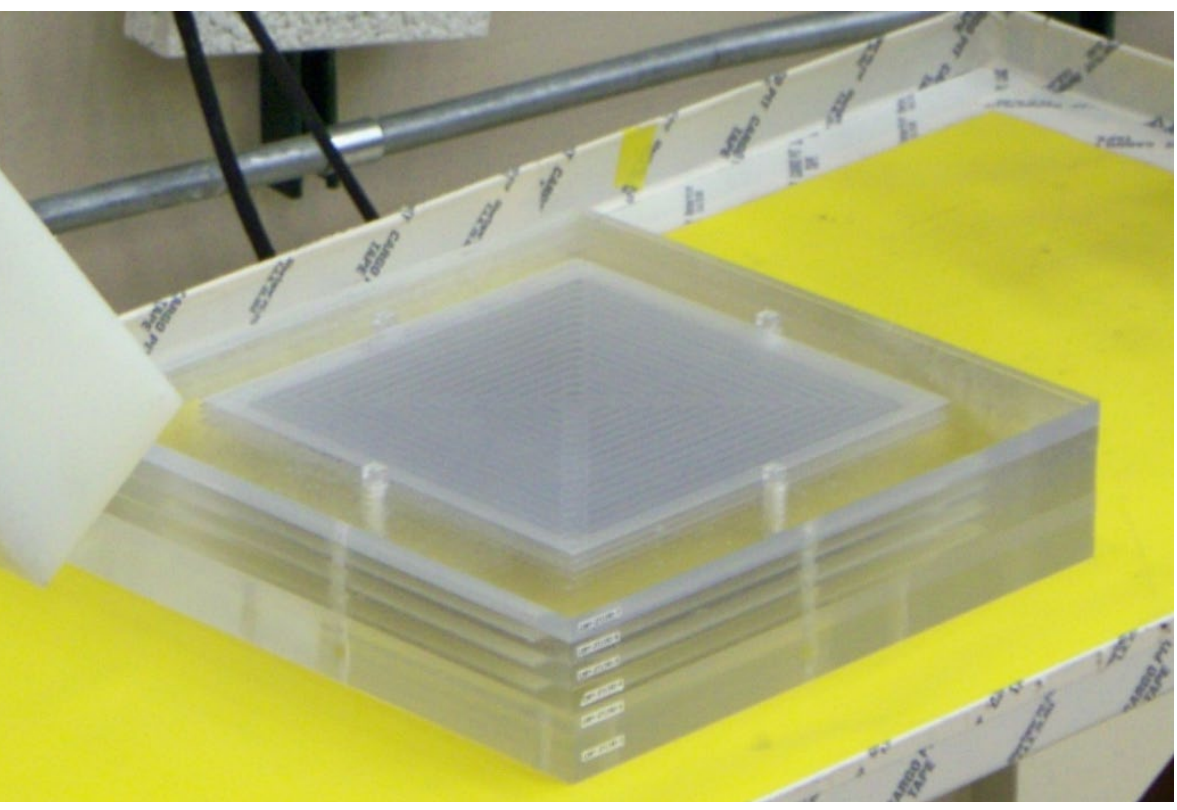




\section{Handstacking}

If we stack enough foil-poly/lucite plate units together, we will achieve a critical configuration
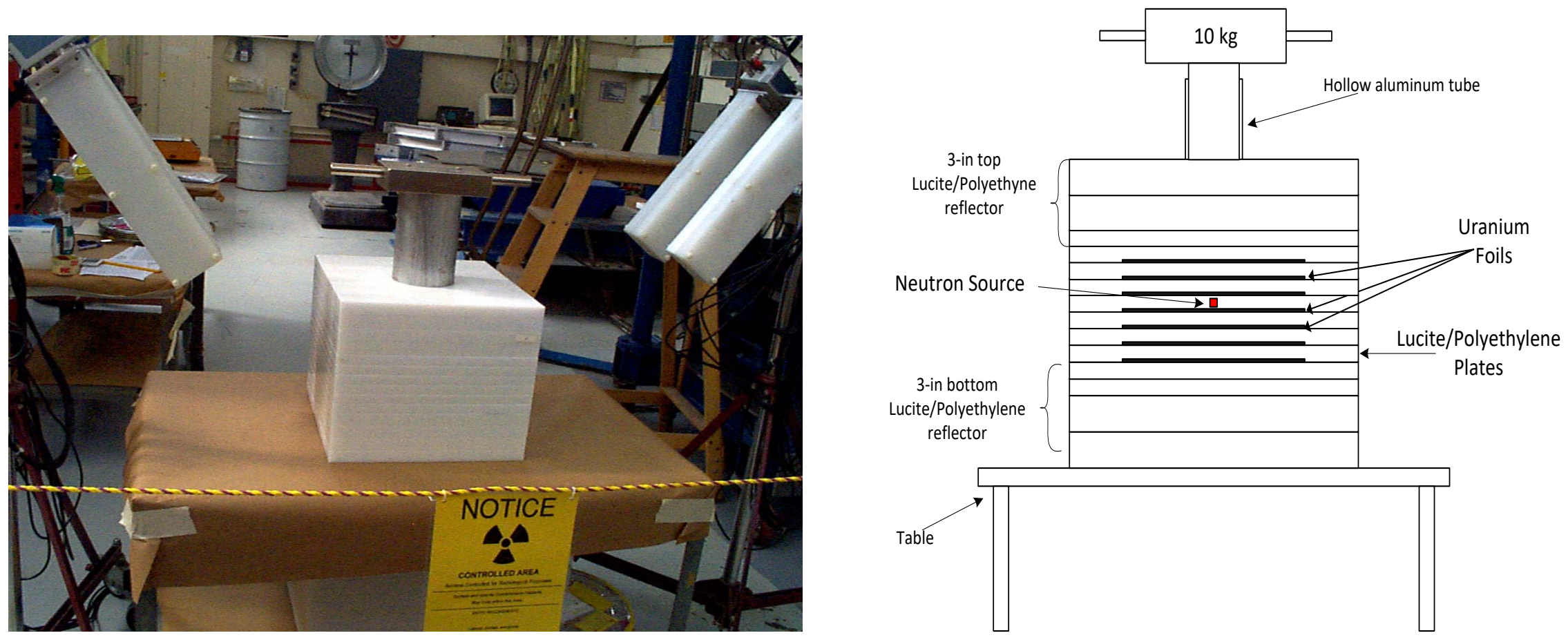

- Configuration:

- Top Reflector: 3" poly/lucite

- Units: X number of poly or lucite/foil "units"

- Bottom Reflector: 3" poly/lucite 


\section{Initial Fuel Load}

Polyethylene $\left(\mathrm{CH}_{2}\right) /$ Lucite Plates

14 " $\times 14$ " x 0.5 "

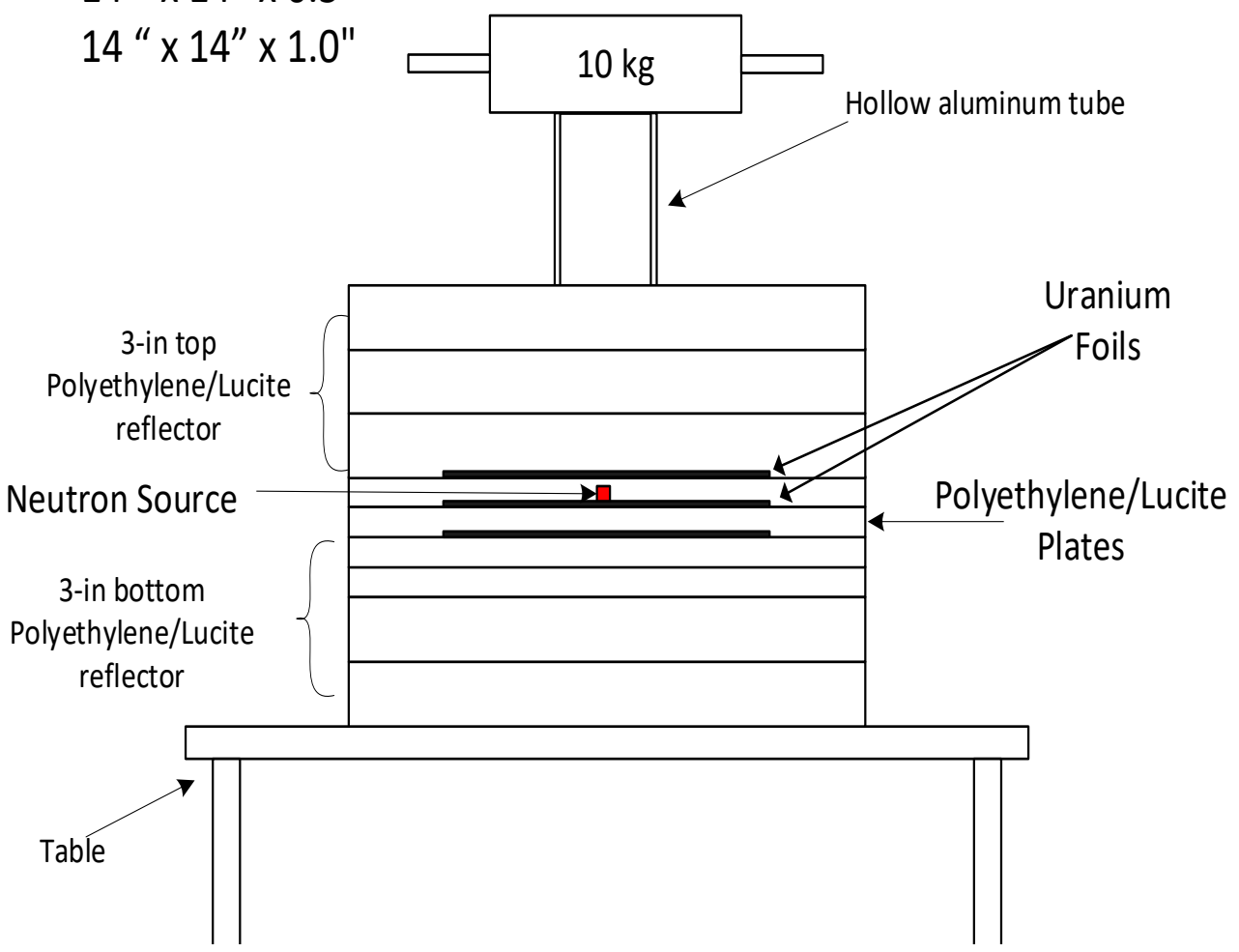

Take a neutron count after configuration is fully assembled. 


\section{Second Loading}
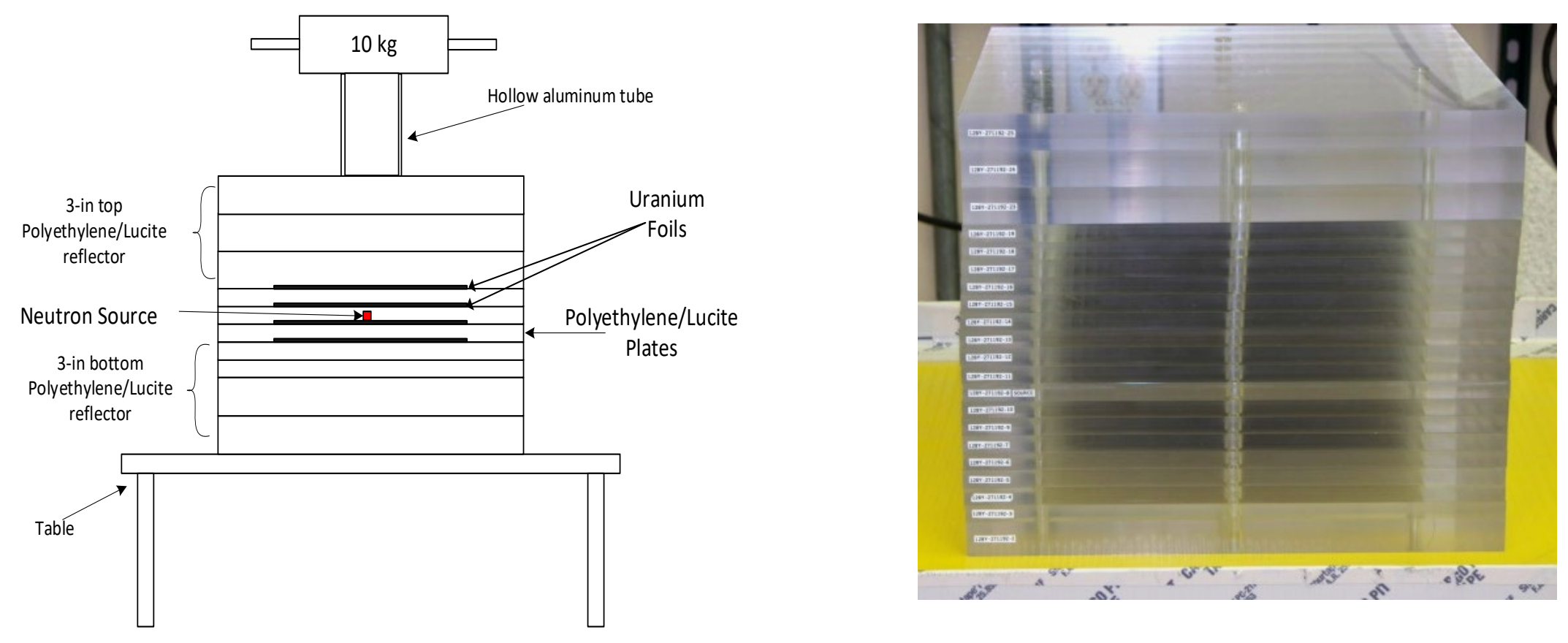

Add one unit and take another neutron count after configuration is fully assembled. 


\section{Approach to Critical - Safety Rules}

-Everyone is responsible for safety.

-Initial and second fuel loadings must be safe.

-Follow the 1/M critical approach curve.

-Limit hand-stacking (3/4-rule).

- Limit rate of fuel addition (1/2-way rule). 


\section{Approach to Critical}

- We do an approach to critical:

- Start with only a few units (very safe, very subcritical)

- By hand, on a cart (handstack)

- Slowly add units to a single stack and use neutron detector to detect neutrons

- Use simple calculations to estimate how many units we need to go critical

- Stop well below our critical estimate! 


\section{Criticality Safety Workshop Data Sheet and \\ Data Graph}

\begin{tabular}{|c|c|c|c|c|c|c|c|c|c|c|}
\hline Units & Counter 1 & Counter 2 & Counter 3 & Counter 4 & Total & M & $1 / \mathrm{M}$ & \begin{tabular}{|c|} 
Predicted \\
Critical
\end{tabular} & $1 / 2$ Way & 3/4 Rule \\
\hline & & & & & & & & & & \\
\hline & & & & & & & & & & \\
\hline & & & & & & & & & & \\
\hline & & & & & & & & & & \\
\hline & & & & & & & & & & \\
\hline & & & & & & & & & & \\
\hline & & & & & & & & & & \\
\hline & & & & & & & & & & \\
\hline & & & & & & & & & & \\
\hline & & & & & & & & & & \\
\hline & & & & & & & & & & \\
\hline & & & & & & & & & & \\
\hline
\end{tabular}

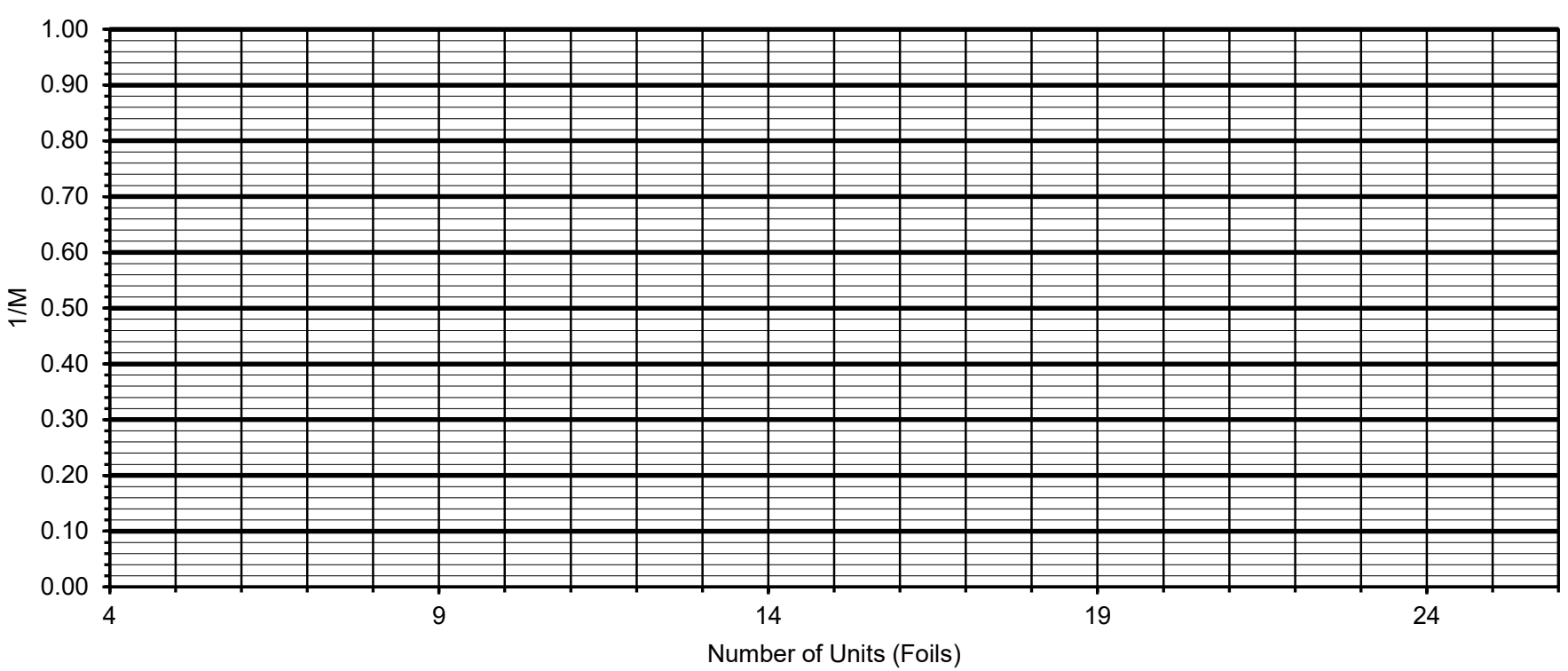




\section{Approach to Critical Rules}

- We have rules that we follow for worker safety when performing the approach to critical (1/M Approach to Critical)

- The first and second configurations must be subcritical

- We linearly extrapolate between the last two data points to estimate the critical configuration

- Half-way rule: A single step can only go up to half-way to the critical estimate

- Three-quarter rule: When handstacking (on the cart), we have to stop when we get to $75 \%$ (3/4) of the estimated critical mass, which corresponds to $k_{\text {eff }}=0.90$ 


\section{Critical Mass Determination (1/M)}

\begin{tabular}{|l|l|}
\hline Step & Action \\
\hline 1 & $\begin{array}{l}\text { Determine base count } \\
\text { rate }\end{array}$ \\
\hline 2 & $\begin{array}{l}\text { Add additional material } \\
\text { (fuel, reflector, etc.). }\end{array}$ \\
\hline 3 & $\begin{array}{l}\text { Measure new count rate, } \\
\text { and plot new } 1 / \mathrm{M} .\end{array}$ \\
\hline 4 & $\begin{array}{l}\text { Extrapolate to critical mass } \\
\text { (1/M) } 0 .\end{array}$ \\
\hline 5 & $\begin{array}{l}\text { Determine safe addition for } \\
\text { next step (based on } 3 / 4 \text { - and } \\
1 / 2 \text {-way rules). }\end{array}$ \\
\hline 6 & $\begin{array}{l}\text { Repeat steps 2-5 to } \\
\text { approach critical. }\end{array}$ \\
\hline
\end{tabular}

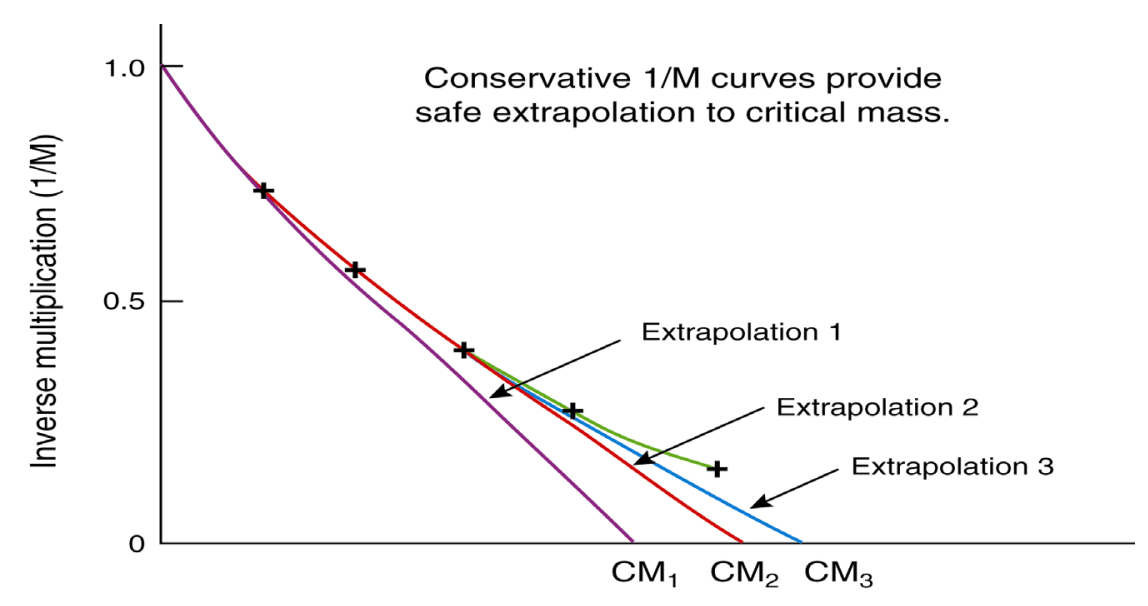

Fuel mass, liquid level, control rod position, etc.

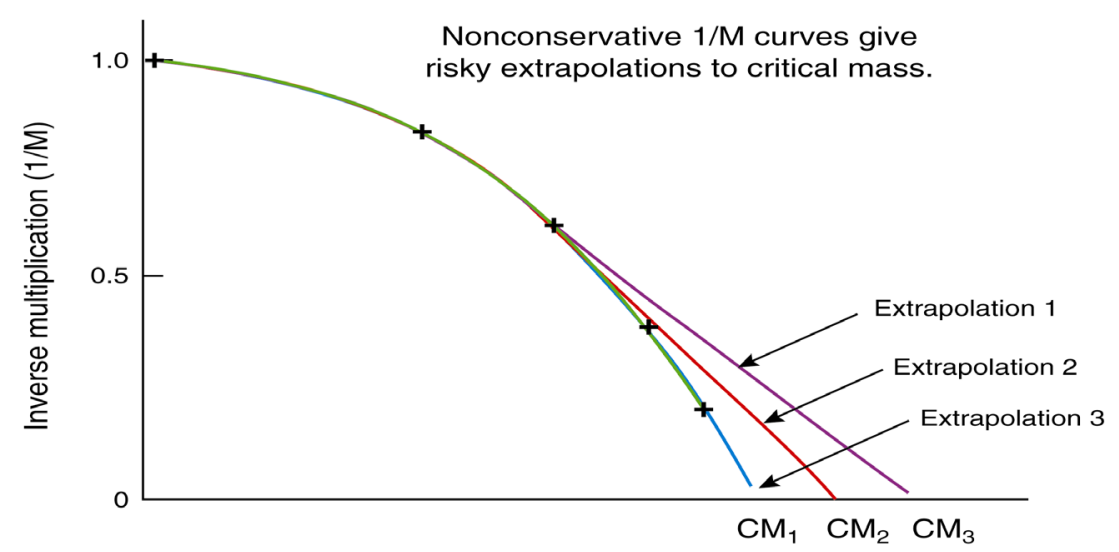

Fuel mass, liquid level, control rod position, etc. 


\section{Approach to Critical Rules}

- Half-way rule:

(\# units in assembly + \# units expected critical)/2

- Three-quarter rule:

\# units expected critical ${ }^{*} 0.75$ 


\section{Approach to Critical Rules}

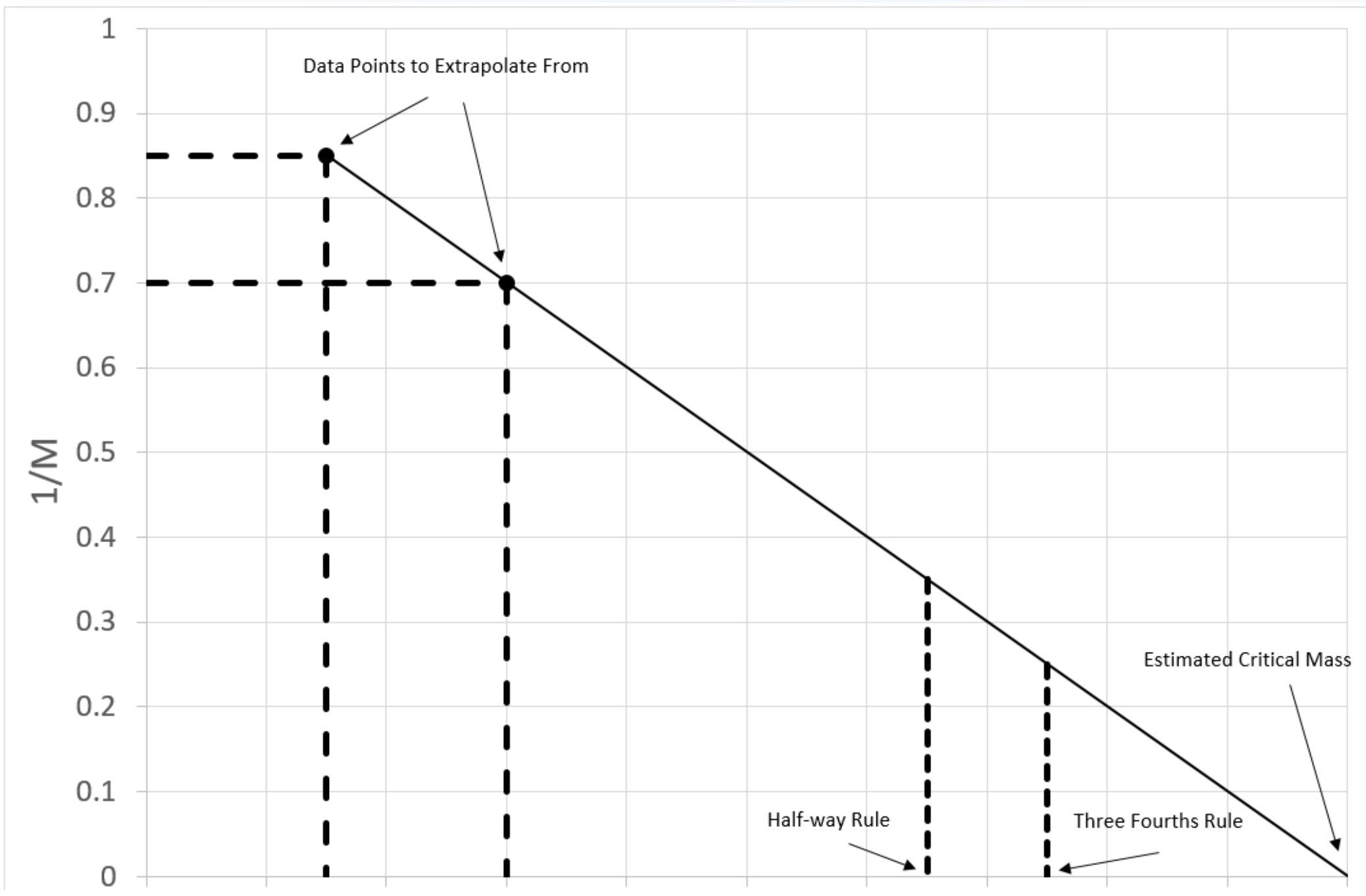

Units in the Stack 


\section{Relative Multiplication}

$\mathrm{C}_{0}=\varepsilon \mathrm{SM}_{0} \Omega$

$\mathrm{C}_{1}=\quad \varepsilon \mathrm{SM}_{1} \Omega$

$\frac{C_{0}}{C_{1}}=\frac{\hat{\varepsilon} \hat{S} \mathrm{M}_{0} \hat{\Omega}}{\mathrm{qSM}_{1} \Omega}=\frac{M_{0}}{M_{1}}$ where

$\mathrm{C}$ is count rate

$\varepsilon$ is the efficiency of the detector

$\mathrm{S}$ is the neutron source $(\mathrm{n} / \mathrm{sec})$

$\mathrm{M}_{0}$ is the initial multiplication (4 foils)

$\Omega$ is the solid angle

$\mathrm{M}_{1}$ is the multiplication for 5 foils 


\section{Module 4 Part 2: Remote Approach to Critical Using the Planet/Comet Assembly}




\section{Approach to Critical}

How do we continue once the Handstack limit is Reached???

- Once we know what the limit is, put that portion on a moveable platform

- Put the additional units on a stationary platform

- Make certain the two stacks are well separated

- What is "well separated"?

- Bring the two stacks together remotely

- Continue to add units to the stationary platform - eventually go critical!

- But where could we find such a machine or machines??? 


\section{Critical Masses of Homogeneous Water-Moderated U(93.2) Soheres}

$\mathrm{H} /{ }^{235} \mathrm{U}$ for $\mathrm{UO}_{2} \mathrm{~F}_{2}$ solution

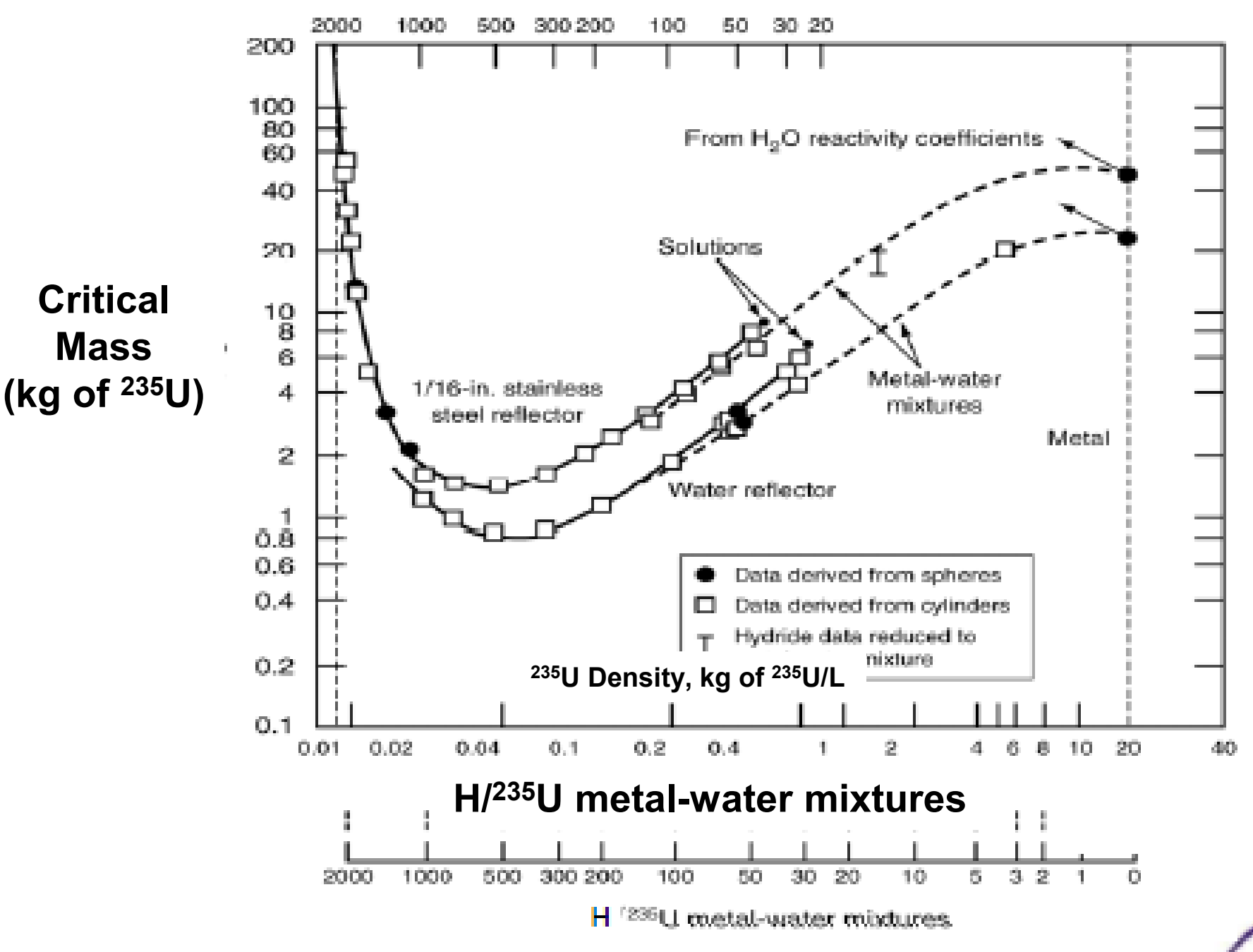




\section{Planet Critical Assembly}

- Planet is a "light-duty," general-purpose, vertical-lift assembly machine.
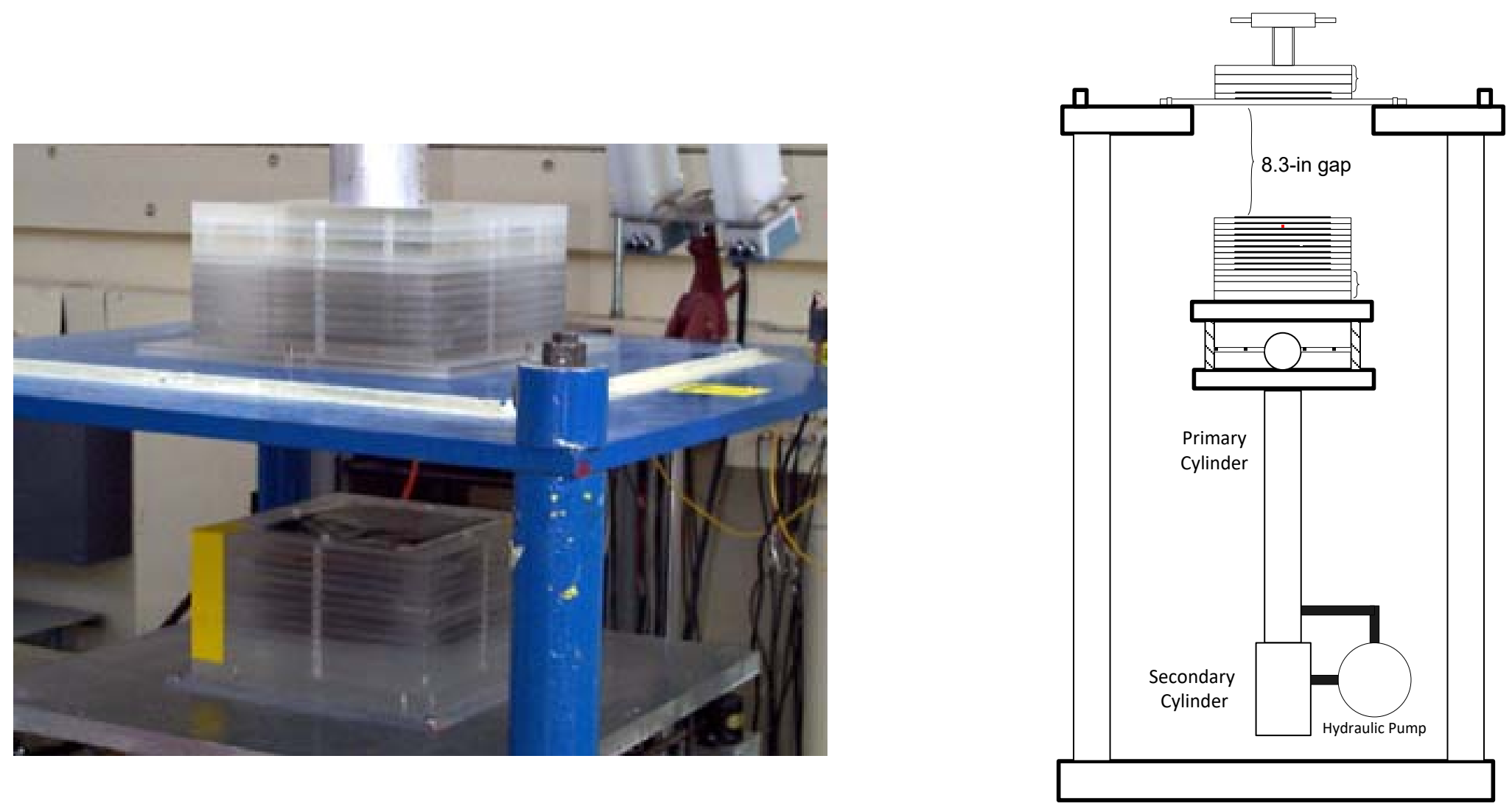


\section{Comet Critical Assembly}

- Comet is a "heavy-duty," general-purpose, vertical-lift assembly machine.
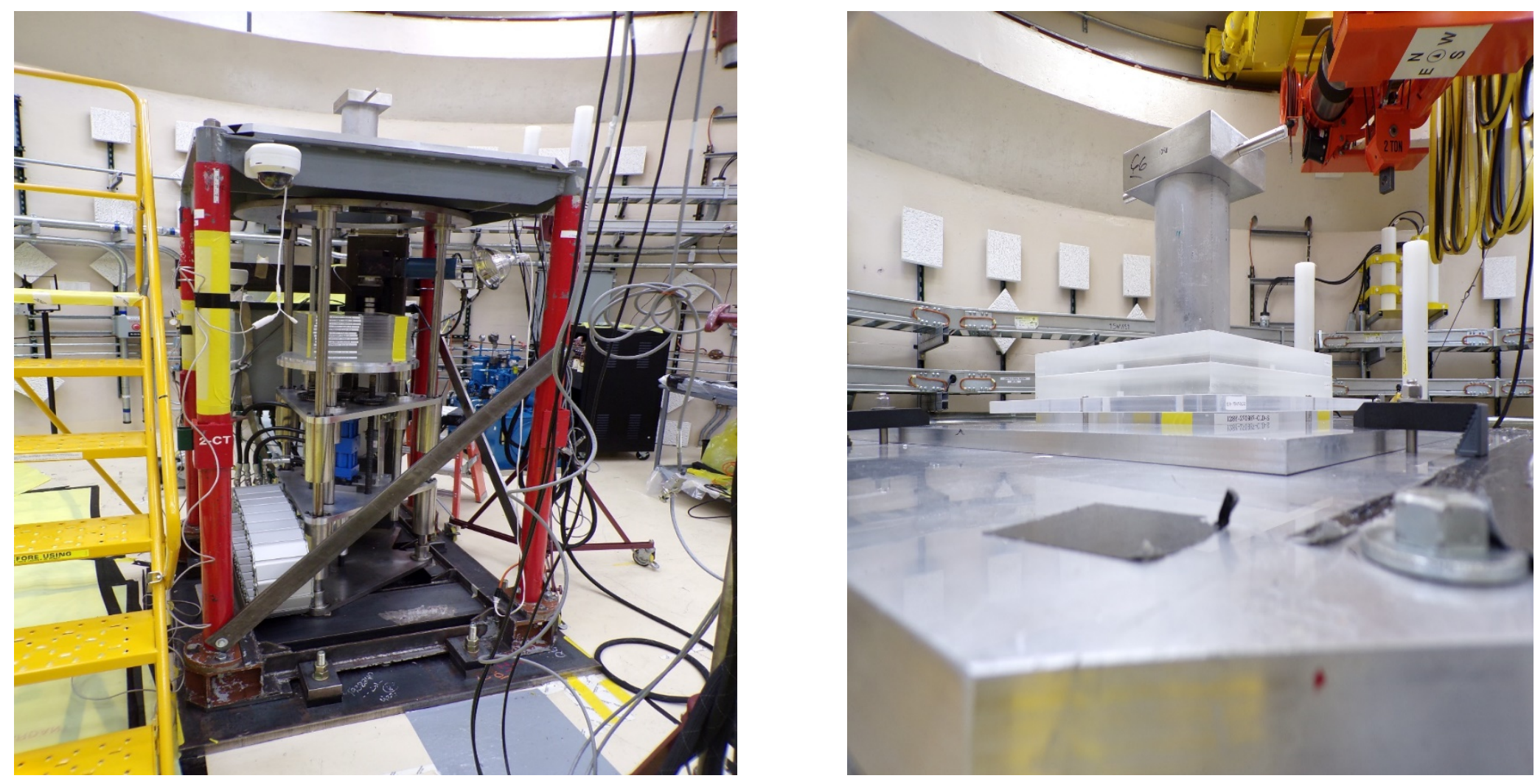


\section{Planet Control Panel Display}

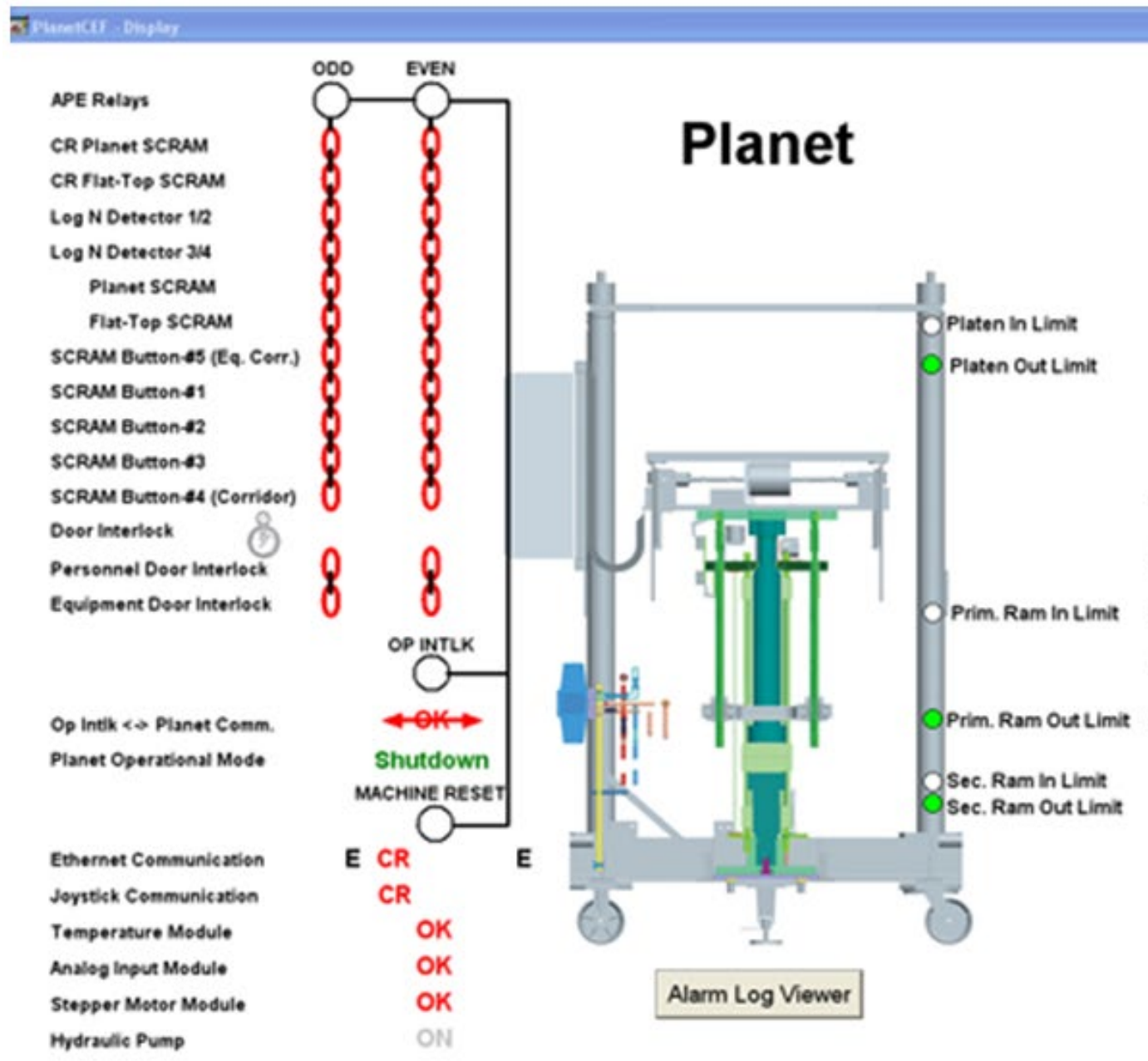

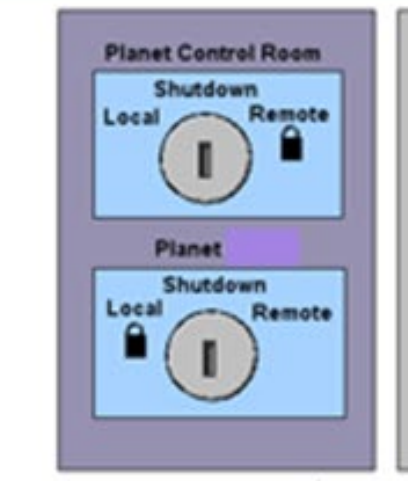

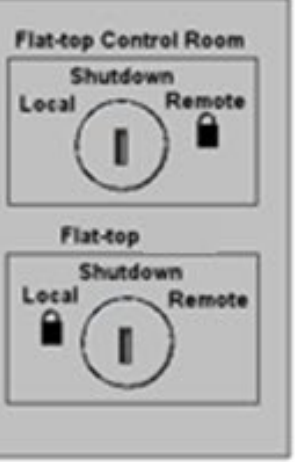

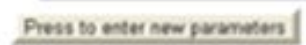
Total Gap $\quad 8.80$ in

Ram Travel $\quad \mathbf{7 . 0}$ in

Platen Travel $\quad 1.8$ in

Slow position $\quad 0.0$ mils

slow speed

0 mils/sec Ambient

\begin{tabular}{|l|r|}
\hline Temperature $\# 1$ & $\mathrm{C}$ \\
\hline Temperature $\approx 2$ & $24.2 \mathrm{C}$ \\
\hline Temperature $\$ 3$ & $22.7 \mathrm{C}$ \\
\hline Temperature $\$ 4$ & $61.7 \mathrm{C}$ \\
\hline Temperature $\$ 5$ & $\mathrm{C}$ \\
\hline Ambient & $23.0 \mathrm{C}$ \\
\hline
\end{tabular}

Hold Left Button for Menu

Gap Distance

8.801 in

Speed $0.000 \mathrm{in} / \mathrm{sec}$

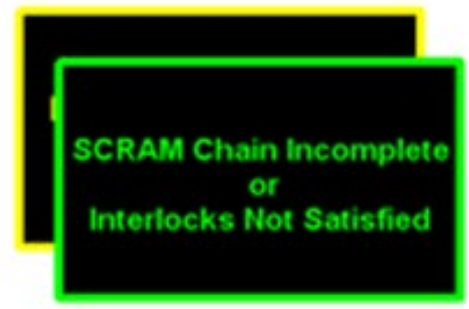

Power

Voltage, 24 V Analog Power Supply Voltage, 24V Olgital Power Supply
OK 


\section{Comet Control Panel Display}

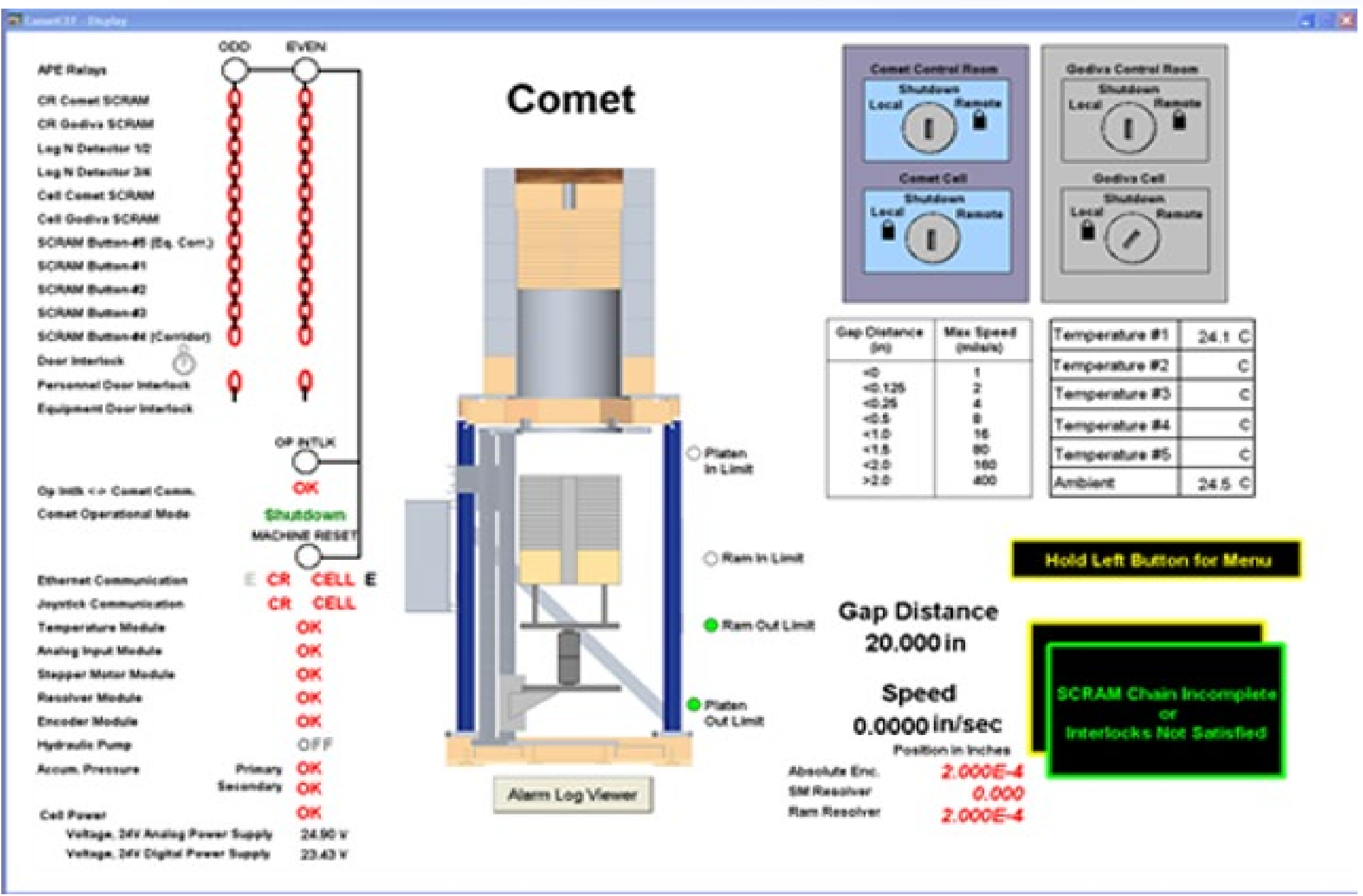


Initial Fuel Loading during Transition to Remote Operations

Never more than the handstack limit $(3 / 4$ rule) on either of the two platforms during fuel loading.

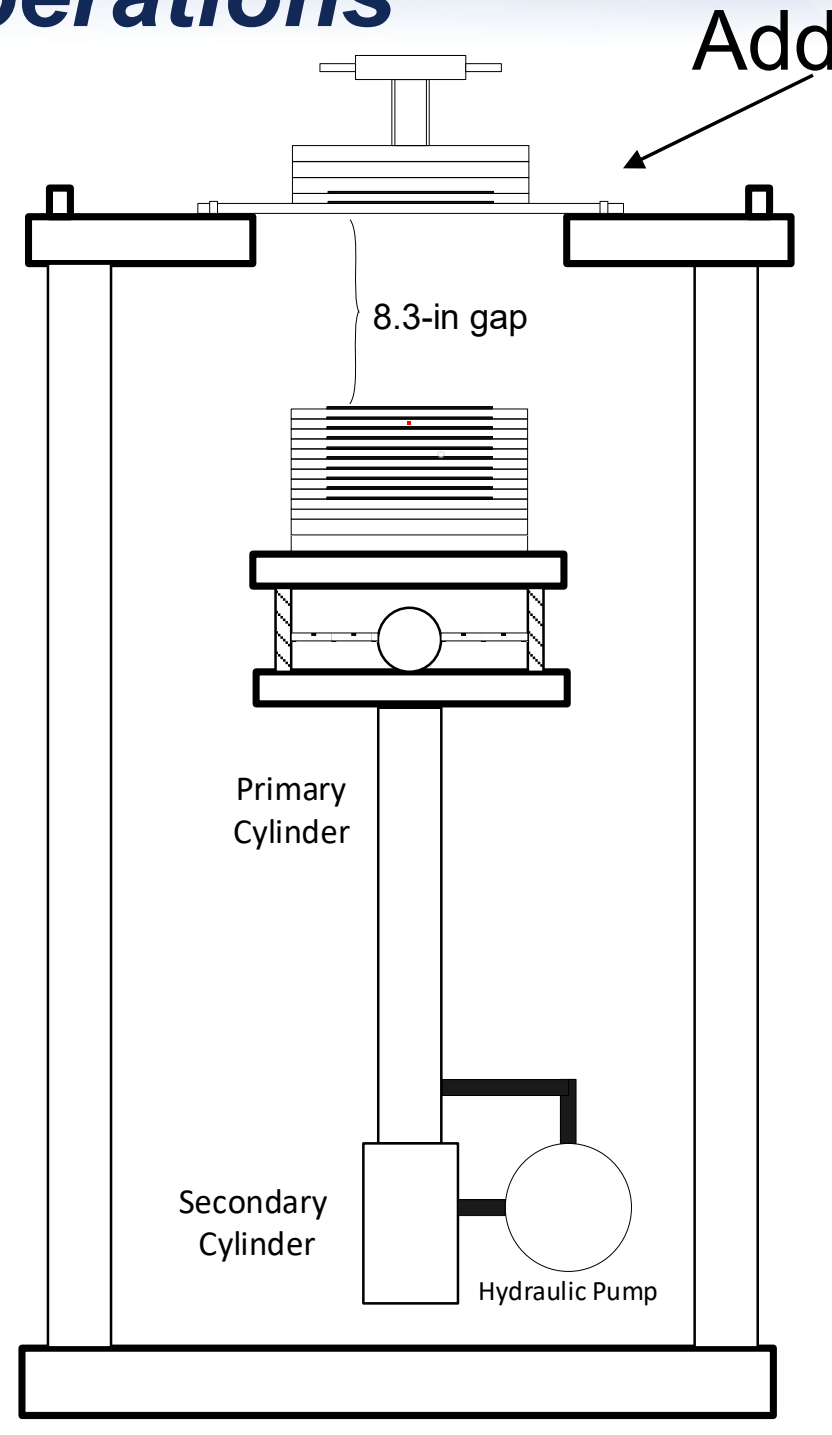

Add Units Here

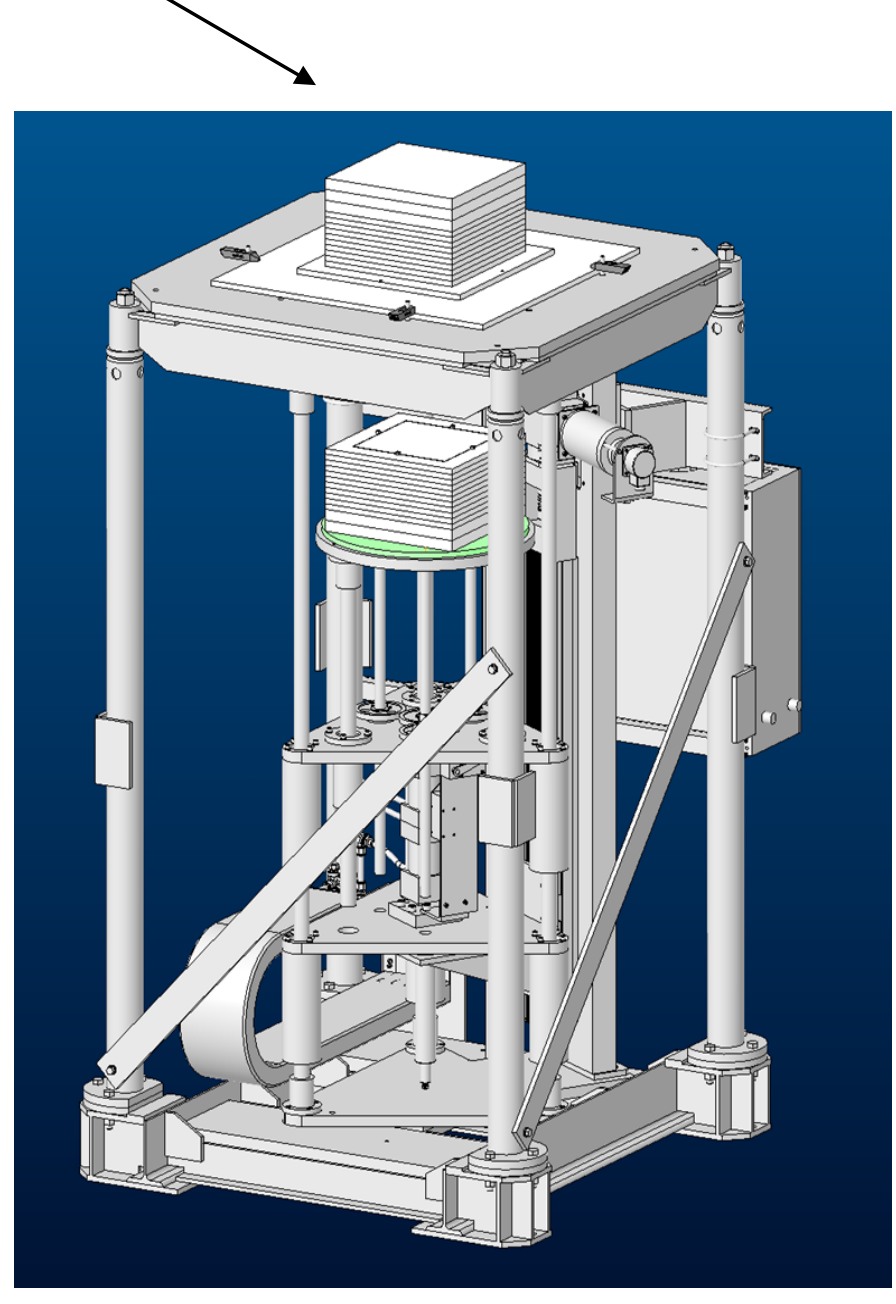




\section{Planet during Remote Operation}

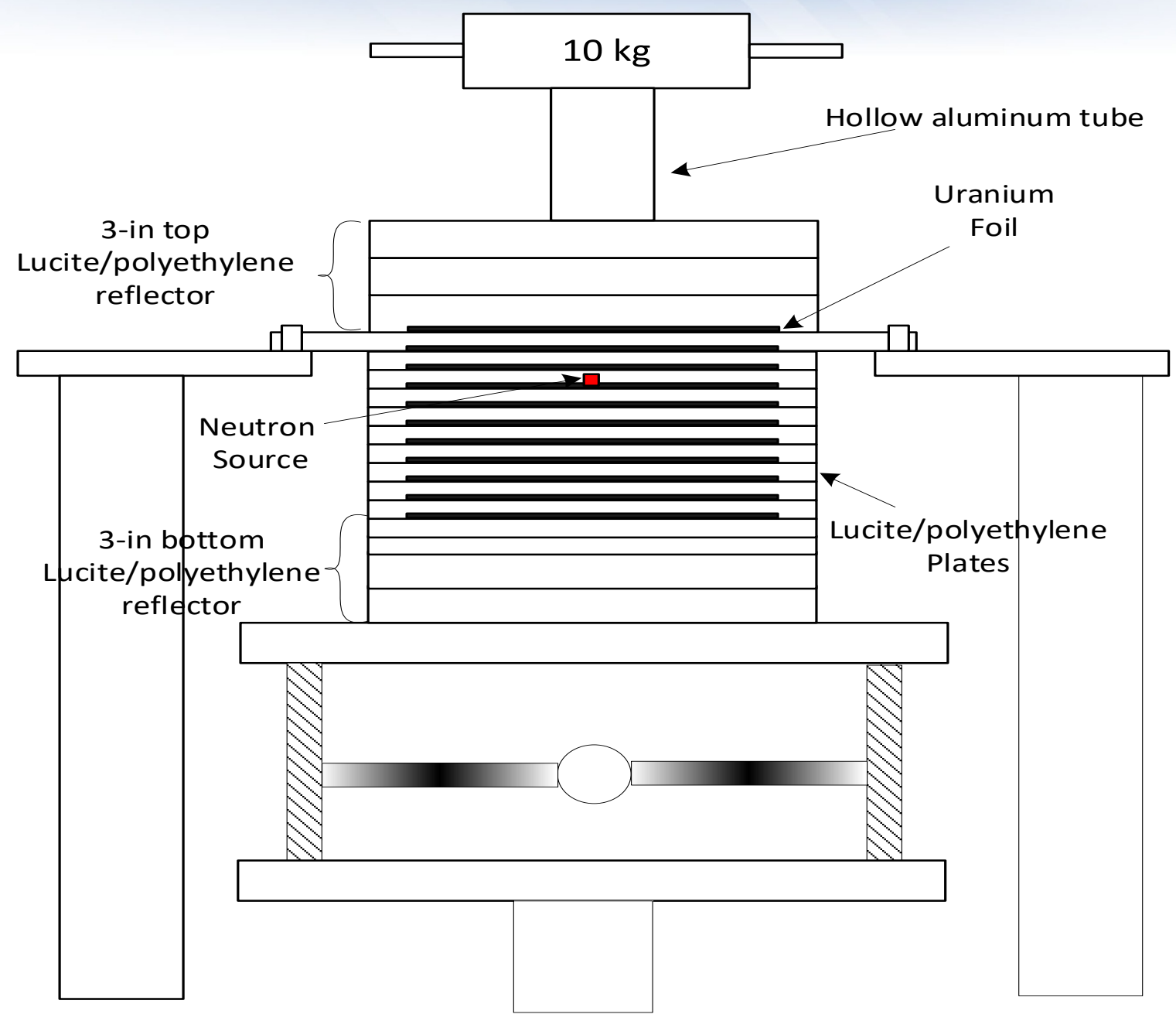

Comet Vertical

Assembly Machine 


\section{Remote 1/M}

$1 / M$ vs Number of Foils (Remote Approach)

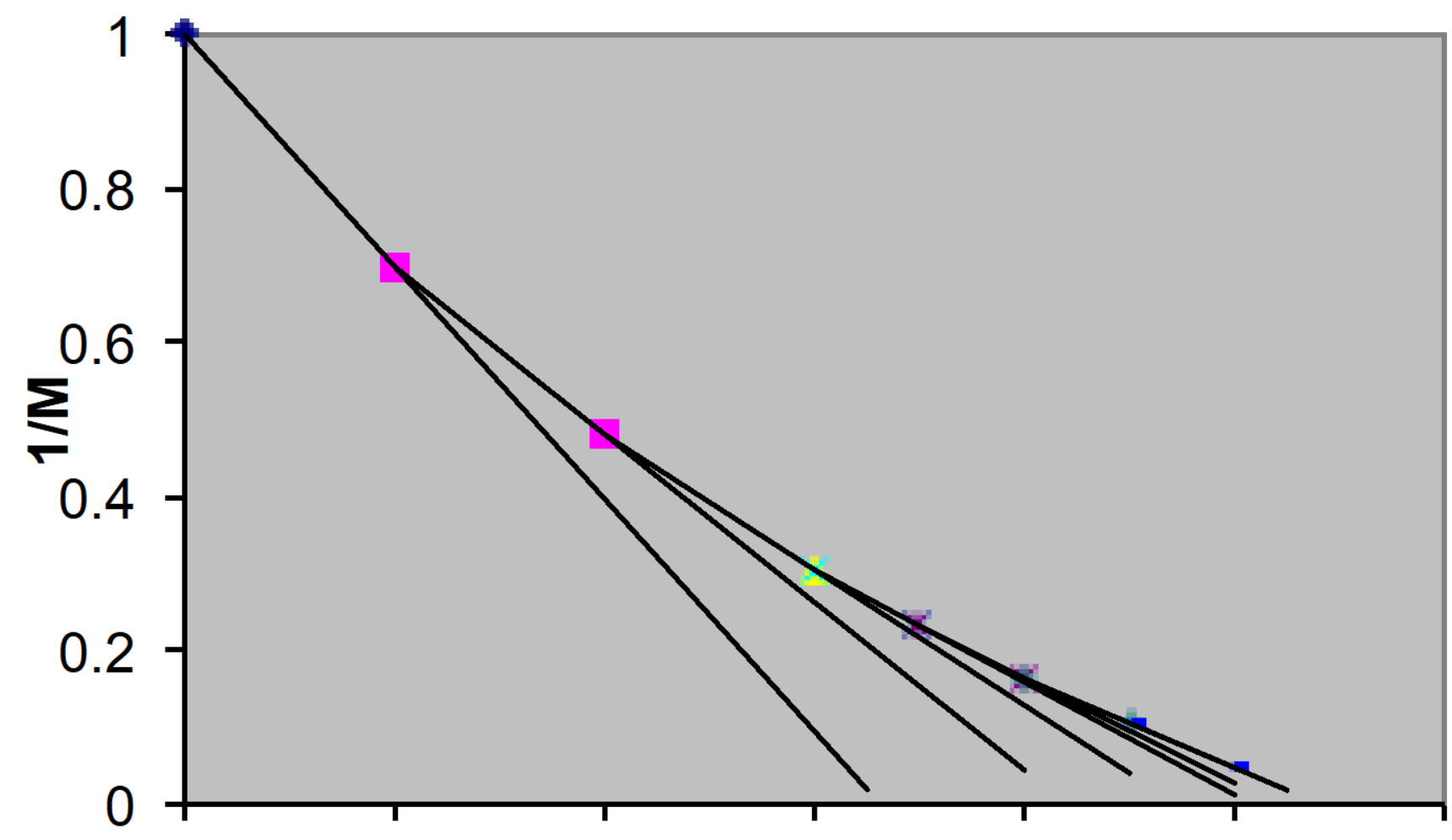

Number of Foils 


\section{Final Approach to Critical}

When the next unit addition will be more than $1 / 2$ way to critical:

-add next Unit,

-use separation distance as unit for 1/M approach, and

-continue until completely closed. 


\section{1/M Using Closure}

1/M vs Separation

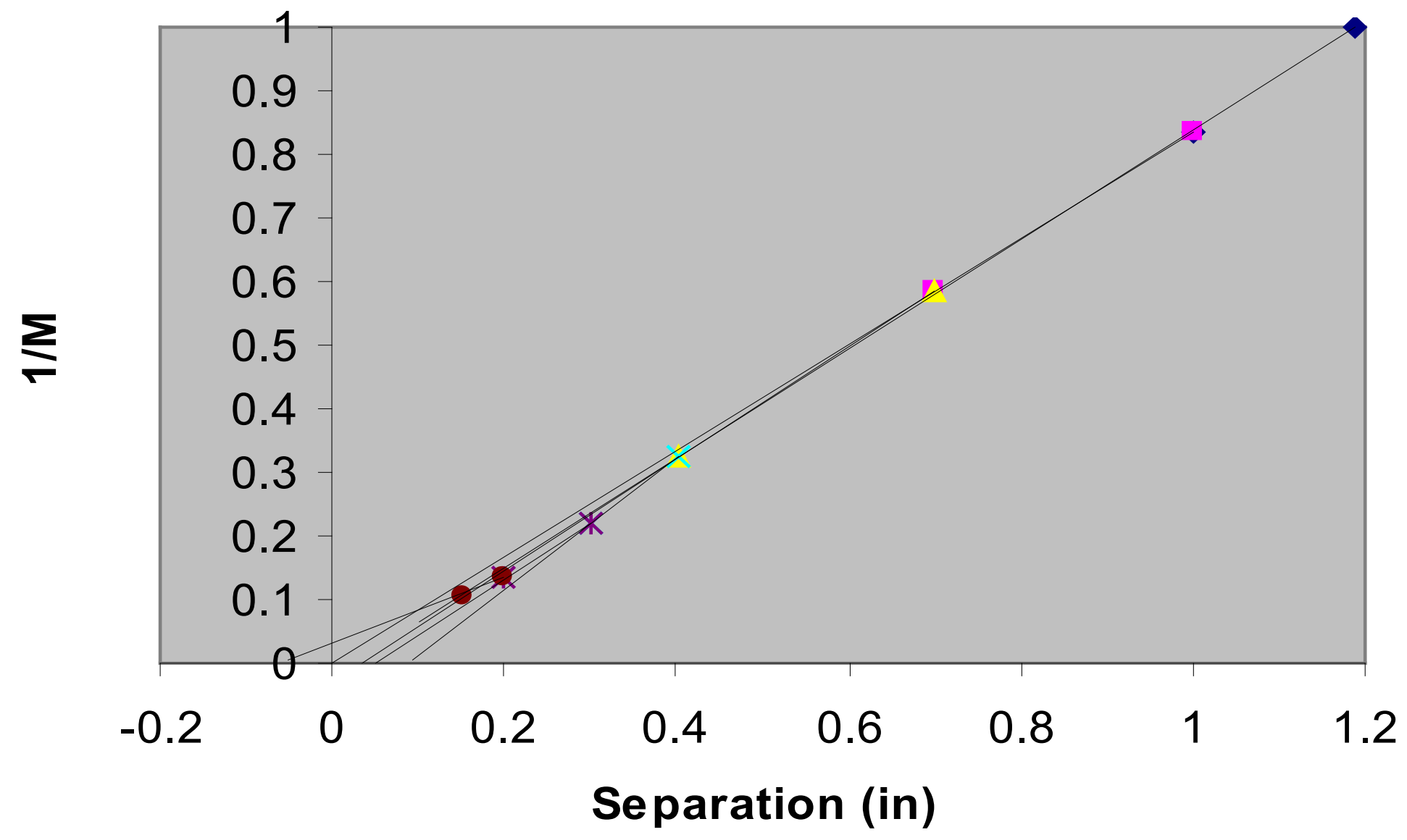




\section{Find Critical}

-Repeat until it is apparent that this unit will go critical.

-Add enough reactivity to be on a positive period.

-Find delayed critical.

-Shim with spacers, adjust the stacking, or use partial foils to adjust the excess reactivity.

-Perform measurements as outlined in the Experiment Plan. 


\section{Inhour Equation (Class Foil Experiment)}

$$
\rho(\$)=\frac{l}{\beta_{e f f} * T}+\sum_{i=1}^{6} \frac{\beta_{i} / \beta_{e f f}}{1+\lambda_{i} T}
$$

where

$\rho(\$) \quad$ is the reactivity in dollars

$\beta_{\text {eff }} / 1$ is the Rossi- $\alpha$ at delayed critical

$\beta_{\text {eff }} \quad$ is the effective delayed neutron fraction for the system

$T \quad$ is the reactor period

$\beta_{\mathrm{i}} / \beta_{\text {eff }}$ is the relative abundance for ${ }^{235} \mathrm{U}$ for each

of the six groups from thermal fission

$\lambda_{i} \quad$ is the decay constant for ${ }^{235} \mathrm{U}$ for each of the six groups from thermal fission

1 is the neutron lifetime of the system 


\section{Parameters Needed for the Inhour}

\section{Equation}

For the Criticality Safety Class Foils Experiment:

$\alpha(\mathrm{DC})=\beta / 1=200 \mathrm{~s}^{-1}$

Decay Constants and Yields for ${ }^{235} \mathrm{U}$ from Thermal Fission ${ }^{1}$

\begin{tabular}{|c|c|c|}
\hline $\begin{array}{c}\text { Group } \\
\text { Index, } \mathrm{i}\end{array}$ & $\begin{array}{c}\text { Decay Constant } \\
\Lambda_{\mathrm{i}} \mathrm{s}^{-1}\end{array}$ & $\begin{array}{c}\text { Relative Abundance } \\
\boldsymbol{a}_{\mathrm{i}}=\beta_{\mathrm{i}} / \beta_{\text {efi }}\end{array}$ \\
\hline 1 & 0.0124 & 0.033 \\
\hline 2 & 0.0305 & 0.219 \\
\hline 3 & 0.111 & 0.196 \\
\hline 4 & 0.301 & 0.395 \\
\hline 5 & 1.14 & 0.115 \\
\hline 6 & 3.01 & 0.042 \\
\hline
\end{tabular}




\section{Graphical Representation of the Inhour NGSP Equation for the Class Foil Experiment

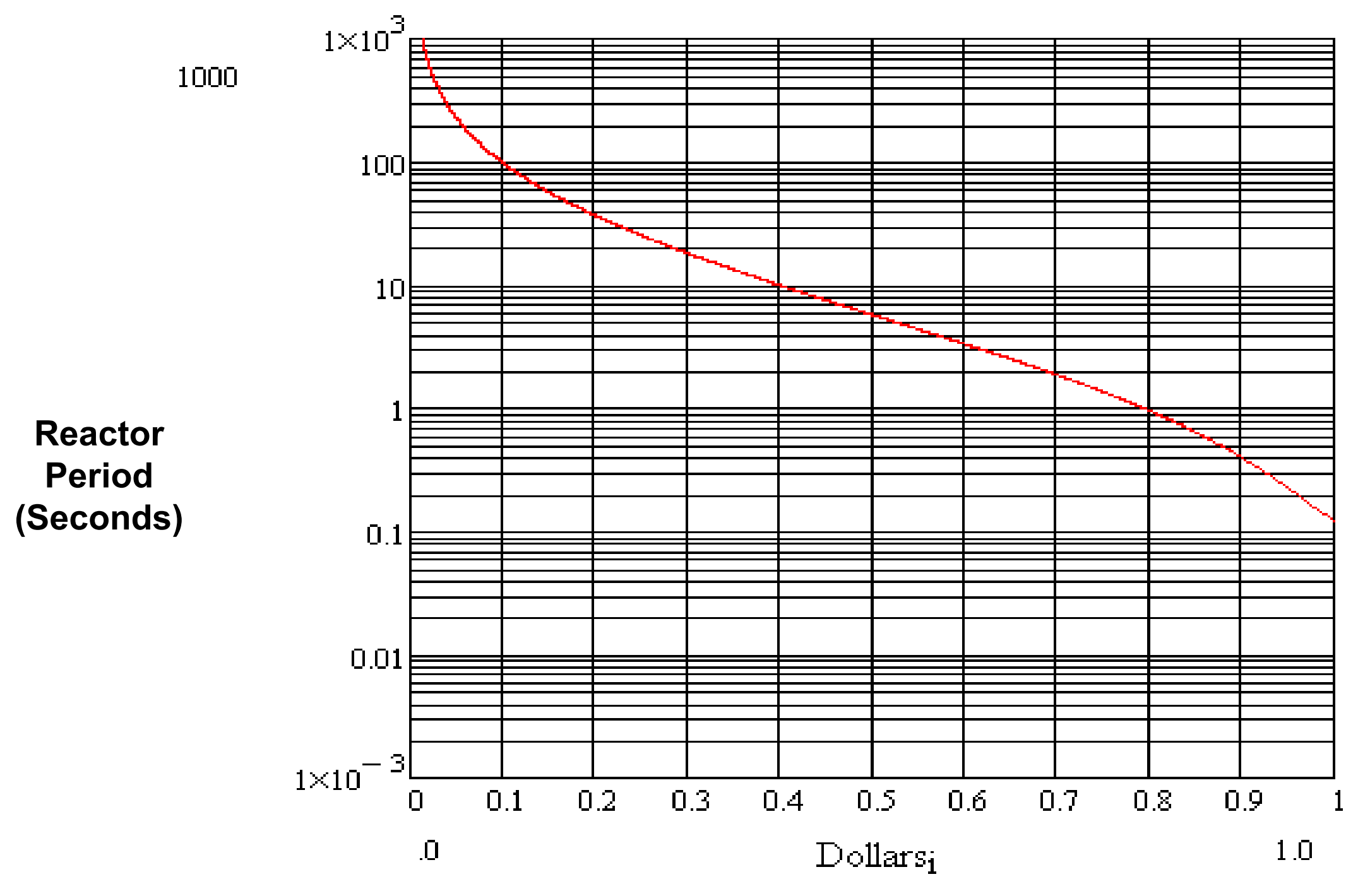

Reactivity (\$) 


\section{References}

1. R. R. Paternoster et al., "Safety Analysis Report for the Los Alamos Critical Experiments Facility (LACEF) and the Hillside Vault (PL-26)," Los Alamos National Laboratory repor, LA-CP-92-235, Rev. 4 (1998).

2. R. Brewer, D. Loaiza, and R. G. Sanchez, "Polyethylene Reflected and Moderated Highly Enriched Uranium System with Silicon," International Handbook of Evaluated Criticality Safety Benchmark Experiments, NEA/NSC/DOC/(95)03/II, HEU-MET-Therm-001.

3. G. R. Keepin, Physics of Nuclear Kinetics, Addison-Wesley Publishing Company, Inc., Reading MA (1965). 


\section{Benchmark Data for Class Foil Experiment}

Uranium Metal Foils

9.0 -in square by 0.003 -in thick

$93.19 \mathrm{wt} \%{ }^{235} \mathrm{U}$

$5.43 \mathrm{wt} \%{ }^{238} \mathrm{U}$

$0.26 \mathrm{wt} \%{ }^{236} \mathrm{U}$

$1.13 \mathrm{wt} \%{ }^{234} \mathrm{U}$

Average Density: $17.25 \mathrm{~g} / \mathrm{cc}$

Lamination:

Two laminated sheets

10 -in square by 0.003 -in thick

Modeled as polyethylene $\left(\mathrm{CH}_{2}\right)$

Average Density: $1.226 \mathrm{~g} / \mathrm{cc}$

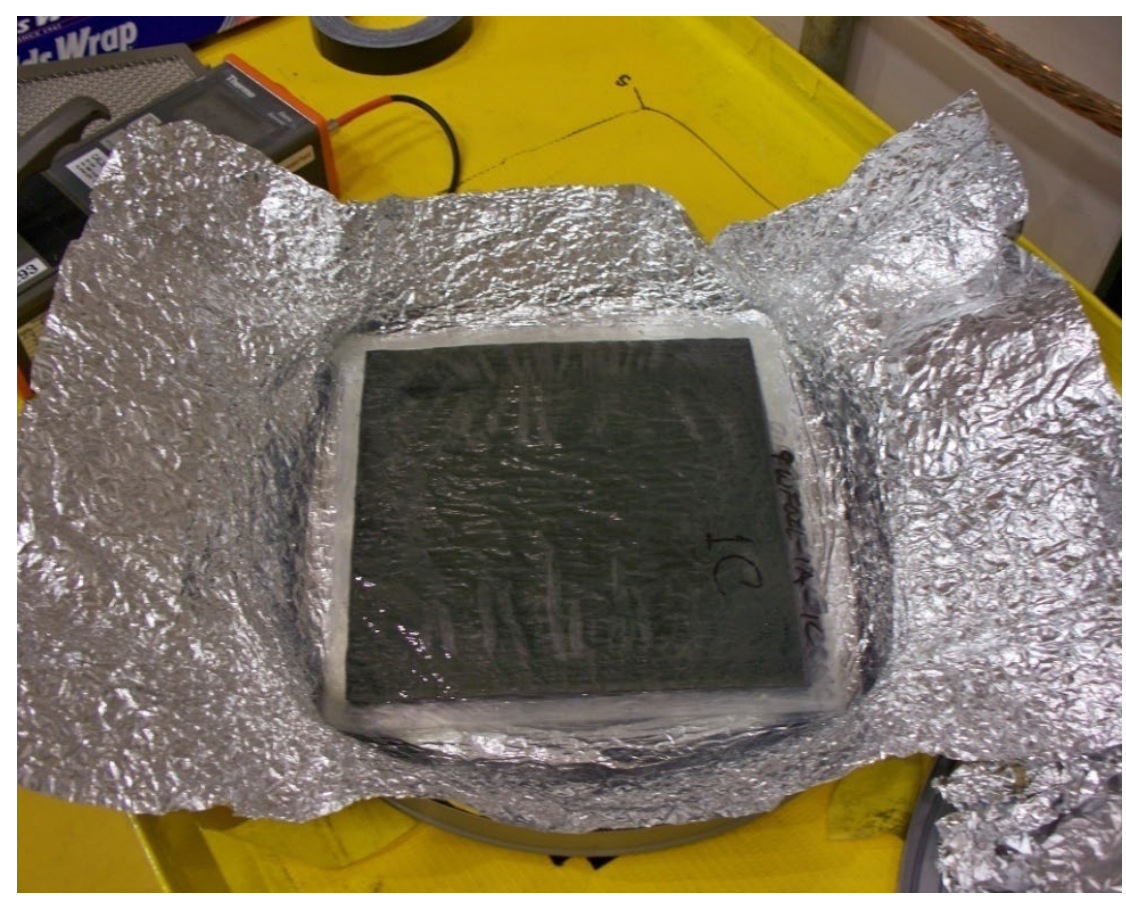

